Article type : Correspondence

588-2017.R1

Correspondence

\title{
Can surgical technology better guide oncological resections in colon cancer?
}

Deborah S Keller, MS MD, Department of Surgery and Interventional Sciences, University College London Hospitals, NHS Trusts, GENIE Centre, University College London, London, UK

Mariana Berho, MD, Professor and Chief, Department of Pathology and Laboratory Medicine, Cleveland Clinic Florida, Weston, FL, USA

Steven D Wexner, MD, FACS, FRCS, FRCS(Ed), Professor and Chief, Division of Colorectal Surgery, Department of Surgery, Cleveland Clinic Florida, Weston, FL, USA

Manish Chand, MBBS MBA FRCS PhD, Department of Surgery and Interventional Sciences, University College London Hospitals, NHS Trusts, GENIE Centre, University College London, London, UK

Drs. Berho, Chand, and Wexner are paid consultants for Novadaq Technologies. Their involvement is outside of the context of this work.

Dr. Wexner is a paid consultant for Karl Storz Endoscopy. His involvement is outside of the context of this work.

Dr. Keller has no disclosures or conflicts of interest.

Corresponding Author:

Mr. Manish Chand, MBA FRCS PhD

Consultant Colorectal Surgeon and Senior Lecturer

Department of Surgery and Interventional Sciences, University College London Hospitals, NHS Trusts, GENIE Centre, University College London

235 Euston Rd, Bloomsbury, London, United Kingdom, NW1 2BU

Tel: 02034475879

Fax: 02034479218

manish.chand@uclh.nhs.uk

Twitter: @ManishChandSurg

This article has been accepted for publication and undergone full peer review but has not been through the copyediting, typesetting, pagination and proofreading process, which may lead to differences between this version and the Version of Record. Please cite this article as doi: 10.1111/codi.13970

This article is protected by copyright. All rights reserved. 


\section{Dear Editor,}

There is little debate that the lymph node yield is an important marker of quality and prognosis in colon cancer and that procuring a minimum of 12 is an acceptable standard of care, and that decreased survival is associated with $<12$ nodes being obtained. (1). The value of obtaining more than 12 nodes or optimal absolute node is contentious. Recently, Del Paggio et al evaluated the association of lymph node yield with nodal positivity and cancerspecific survival after curative resection for stages II/III colon cancer, concluding that thresholds for optimal survival are associated with yields greater than 12(2). However, the authors and other studies have shown the number of nodes examined above 12 does not associate with staging, use of adjuvant therapy, or significant survival benefit in colon cancer(3). So why strive for more nodes?

The number of nodes examined depends on many variables, including the surgeon's technique of lymphadenectomy and the pathologist's meticulous dissection with specimen. It is reasonable to suggest that the extent of resection should be based on anatomical and embryological landmarks, not the premise of getting more nodes. This concept is illustrated by the "en bloc" total mesorectal excision (TME) in rectal cancer(4). The concept of Complete Mesocolic Excision (CME) with Central Vascular Ligation in colon cancer is meant to be analogous to the TME but the concepts are not directly transferable. While some evidence suggests $\mathrm{CME}$ is associated withimproved survival outcomes, it is debatable whether this is related to an increased number of nodes. (6). AS such, considering the the increased morbidity with increased nodal yield, , there is insufficient evidence to recommend its’ widespread adoption. 
Perhaps the right answer is to perform a more accurate dissection, not just procure more nodes. Techniques to improve nodal assessment and supplement pathological staging, such as radioimmunoguided surgery (RIGS) and sentinel lymph node (SNL) mapping have been described although their their role remains poorly defined. . The most meaningful tool for guiding the optimal resection margins may be intra-operative fluorescence imaging (FI) with a fluorophore, such as indocyanine green (ICG). FI allows direct visualization of the tumor with its draining nodal basin, the sentinel node(s), and any aberrant nodes outside of the planned resection field, thus permitting a more precise mesenteric lymphadenectomy, obviating a reliance on lymph node numbers alone.. FI can also show the watershed areas in the mesentery and define the lateral extents of lymphatic spread, allowing a CME-style dissection to be completed. This type of lymphatic mapping may permit improved intraoperative cancer-targeting techniques.

The clinical implications for this precision-guided surgery could impact staging, patient prognosis, and guide adjuvant therapy recommendations the way simply harvesting more nodes could not. Studies are underway to validate these clinical assumptions with FI, and technical details are being standardized. In the meantime, ensuring pathological scrutiny of our surgery, we must continue to strive for optimal resections based on oncological principles to obtain a minimum of 12 nodes for our patients the best outcomes.

Keywords: Colon cancer; complete mesocolic excision; central vascular ligation; lymph node yield; fluorescence lymphangiography; fluorescence imaging; indocyanine green 


\section{References}

1. Chang GJ, Rodriguez-Bigas MA, Skibber JM, Moyer VA. Lymph node evaluation and survival after curative resection of colon cancer: systematic review. J Natl Cancer Inst. 2007;99:433-441.

2. Del Paggio JC, Peng Y, Wei X et al. Population-based study to re-evaluate optimal lymph node yield in colonic cancer. Br J Surg. 2017

3. O'Shea A, Aly O, Parnaby CN, Loudon MA, Samuel LM, Murray GI. Increased lymph node yield in colorectal cancer is not necessarily associated with a greater number of lymph node positive cancers. PLoS One. 2014;9:e104991.

4. Heald RJ, Husband EM, Ryall RD. The mesorectum in rectal cancer surgery--the clue to pelvic recurrence? Br J Surg. 1982;69:613-616.

5. Bertelsen CA, Kirkegaard-Klitbo A, Nielsen M, Leotta SM, Daisuke F, Gögenur I. Pattern of Colon Cancer Lymph Node Metastases in Patients Undergoing Central Mesocolic Lymph Node Excision: A Systematic Review. Dis Colon Rectum. 2016;59:1209-1221. 